\title{
Research on the Application of Insurance Funds in China: based on the Foreign Experience
}

\author{
Xuna Han ${ }^{1}, \mathrm{Li} \mathrm{Li}^{1,2,3,}$, , Lei Xiao ${ }^{4}$ \\ ${ }^{1}$ Pan-Asian Business School , Yunnan Normal University, Kunming 650092, China \\ ${ }^{2}$ Yunnan Association for Promotion of Trans-Asian Financial Cooperation and Development, \\ Kunming,650092, China \\ ${ }^{3}$ Champion Property \& Casualty Insurance Co., Ltd., Kunming 650228, China \\ ${ }^{4}$ School of Marxism Studies, Kunming University, Kunming 650092, China \\ 我国保险资金运用分析：基于国外经验的借鉴 \\ 韩旭娜 ${ }^{1}$, 李丽 ${ }^{1,2,3, *}$, 肖否 ${ }^{4}$ \\ ${ }^{1}$ 云南师范大学泛亚商学院, 昆明 650092 , 中国 \\ 2 云南省泛亚金融合作发展促进会, 昆明 650092, 中国 \\ ${ }^{3}$ 诚泰财产保险股份有限公司, 昆明 650228 , 中国 \\ ${ }^{4}$ 昆明学院马克思主义学院, 昆明 650092 , 中国
}

\begin{abstract}
The application of insurance funds is the main business of insurance industry, is also an important source of profit for insurance companies, as well as an important means of risk prevention. China's insurance fund scale is huge, as of 2017, the total assets of the insurance industry amounted to 16.3 trillion yuan. Therefore, it is of great significance to explore the application of insurance funds to the management and development prospects of insurance industry. This paper systematically analyzes the problems existing in the application of insurance funds in China, and

第一作者简介: 韩旭娜 (1990-), 女, 汉族, 河北石家庄人, 云南师范大学泛亚商学院硕 士研究生。研究方向: 风险分析, 旅游经济。 邮箱: han_352375636@qq. com

*通讯作者简介: 李丽 $(1980-)$, 女, 汉族, 湖北襄阳人, 云南师范大学泛亚商学院副教 授, 硕士生导师, 研究方向: 数量经济。邮 箱: 43063010@qq. com
\end{abstract}

draws on the foreign advanced experience, puts forward corresponding measures to provide some reference for the Government and relevant departments.

Keywords : insurance fund; application of funds; foreign experience reference

\section{摘要}

保险资金运用是保险行业的主要业务, 也是保险公司重要的利润来源, 以及风险防 范的重要手段。我国保险资金规模庞大, 截 至 2017 年, 保险业总资产达 16.3 万亿元。 因此, 探索保险资金运用对保险业的经营管 理及发展前景都有重要意义。本文系统分析 我国保险资金运用中存在的问题, 并借鉴国 外先进经验, 提出相应的解决措施, 以期给 政府及相关部门提供一定的借鉴意义。

关键词: 保险资金; 资金运用; 国外经验借 鉴

1. 引言

中共十九大以来, 我国社会主要矛盾已 经转化为人民日益增长的美好生活需要和 
不平衡不充分的发展之间的矛盾。我国经济 的发展, 促进人民收入水平提高, 居民用于 购买保险的资金总量日益加大。中国银保监 会统计数据报告显示: 2017 年保险业实现原 保费收入约 3.7 万亿元, 同比增长 $18.16 \%$; 保险资金运用余额约 15 万亿元，较年初增 长 $11.42 \%$ 。其中, 银行存款和债券占比 47. 51\%。保险资金规模的不断加大，使得保 险资金运用中暴露的问题日益突出。

2018 年 4 月 1 日起实施的《保险资金运 用管理办法》规定, 我国保险资金的运用渠 道主要包括: 银行存款、买卖债券、股票、 证券投资基金份额等有价证券、投资不动 产、投资股权及中国保监会规定的境外投资 等。保险集团 (控股) 公司、保险公司应当 按照 “集中管理、统一配置、专业运作” 的 要求, 实行保险资金的集约化、专业化管理。 但在实践中, 金融乱象依然存在, 组织机构 和人员违法违规现象严重, 保险业作为金融 体系的一个重要分支, 同样面临重大风险。 2015 年 7 月份开始持续一年的 “宝万之争”, 给金融资本界敲响了警钟。“宝万之争”之 始, “宝能系” 将其子公司前海人寿的保险 资金 104.22 亿元用于购买万科公司股权, 意图谋取私欲, 扰乱金融市场环境, 给保险 业带来极大冲击。因此, 本文深入探究保险 资金运用过程中存在的问题，并且借鉴国外 先进经验, 对我国保险资金运用提出合理化 建议, 以期给我国政府及相关部门提供参 考。

\section{2. 文献回顾}

胡宏兵、郭金龙 (2009) 从保险资金运 用与资产负债匹配管理的基本理论、美国保 险资金运用的考察、我国保险资金运用现状 及问题、改善我国保险资金运用状况的策略 四个方面，对保险资金运用的相关问题进行 了深入探讨 ${ }^{[1]}$ 。王姝 (2013) 针对我国保险 资金运用现状、问题的分析和对国际经验的 借鉴, 提出要创新保险资金运用方式, 完善 保险资金运用监管, 推动保险企业建立风险 内控制度, 提高了保险企业的资金运用能力 ${ }^{[2]}$ 。黄英君 (2010) 将动态风险管理方法 VaR 引入中国保险资金运用的风险管理中, 对中 国保险资金运用进行实证分析, 并提出相关
政策建议 ${ }^{[3]}$ 。靳珂 (2016) 认为可以运用 VaR 研究方法来管控保险资金的投资风险 ${ }^{[4]}$ 。张 健 (2009) 认为在当前风险管理现实条件下, 科学投资决策和运作架构, 强化交易流程控 制和风险防范监测, 完善激励约束机制, 以 持续推进保险资金运用全面风险管理具有 较强的实践意义 ${ }^{[5]}$ 。杨明生 (2008) 回顾了保 险资金运用的发展路径, 得出结论: 为保证 今后保险资金有效运用与发展, 需要进一步 加强和改善保险资金运用监管 ${ }^{[6]}$ 。曲扬 （2008）比较了以直接融资为主的金融体系 和以间接融资为主的金融体系间, 保险资金 运用的状况, 总结经验为我国保险资金的运 用提供了有益的借鉴 ${ }^{[7]}$ 。张立勇 (2012) 认 为将西方发达国家保险资金运用成功的经 验和做法中国化, 可以使我国保险业获得跨 越式发展 ${ }^{[8]}$ 。

综合分析发现, 国内学者在研究保险资 金运用问题时, 多侧重对保险资金运用风险 的管理, 这在一定程度上推动了我国保险业 的发展。但对保险资金的运用渠道、运用效 率研究尚少, 没有形成完整的体系, 保险资 金运用方面尚有诸多问题亟待解决。

\section{3. 我国保险资金运用发展历程}

我国保险资金运用发展情况大致可以 分为以下五个阶段:

第一阶段 (1984-1988 年), 1984 年 11 月, 国务院颁布了《关于加快发展我国保险 事业的报告》, 允许保险公司开展资金运用, 但范围仅限于存款、购买国债、流动资金贷 款和金融债券买卖, 同时由中国人民银行对 运用额度制订年度指令性计划。因此, 该时 期的资金运用比例较低, 收益不高。

第二阶段（1988～1991 年), 1988 年我 国经济出现过热现象, 国家开始实施紧缩政 策, 保险资金运用政策也随之收紧。保险资 金运用范围被严格限定为流动资金贷款、企 业技术改造贷款、购买金融债券和银行同业 拆借, 并开始采取了担保和银行承兄汇票抵 押等风险控制手段。

第三阶段 (1991 1995 年), 1991 年后, 我国经济体制转型取得突破, 经济形势开始 好转。保险资金运用也随之再度活跃起来, 并很快进入到房地产、有价证券、信托等热 
点领域。但由于法规制度不健全、投资权限 分散且经验不足等原因, 资金运用很快出现 了无序和失控的局面, 各保险公司资产质量 都出现了不同程度的恶化。

第四阶段 (1995 1998 年), 1995 年 10 月, 我国颁布第一部《保险法》, 开始依法 对前期保险资金运用中出现的无序现象进 行整顿。保险资金运用范围被限定为银行存 款、买卖政府债券、金融债券和国务院规定 的其他资金运用形式, 同时规定保险资金不 得用于设立证券经营机构和向企业投资。

第五阶段 (1998 年至今), 1998 年 11 月 中国保险监督管理委员会成立, 标志着我国 保险资金运用进入到了规范监管阶段。2002 年和 2009 年, 国家先后两次修改了《保险 法》, 为保险资金运用政策的进一步完善提 供了制度空间。随后, 《保险资金运用管理 暂行办法》、《险资金投资股权暂行办法》、 《保险资金投资不动产暂行办法》等一系列 保险资金运用的规定相继出台, 标志着我国 保险资金运用政策体系已初步形成。

现阶段是我国保险业飞速发展时期, 但 是由于我国保险业起步晚, 制度不健全, 因 此, 保险业作为我国金融体系的重要组成部 分, 其在监管制度、资产负债管理、风险控 制、公司治理等方面存在很大问题。

\section{4. 现阶段我国保险资金运用现状}

本文中, 我们选取 2012-2016 年保险 数据, 对我国保险资金运用状况进行综合分 析, 数据来源于《中国统计年鉴》及各年国 民经济统计公报。

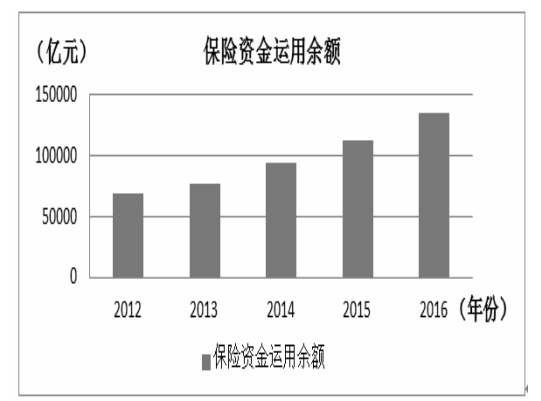

图 1 2012-2016 年保险资金运用余额

图 1 显示我国保险资金运用余额呈迅速
上升趋势, 从 2012 年的 68542.58 亿元上升 到 2016 年的 133910.67 亿元, 其中 2014 到 2016 年上升速度最快。说明我国经济改革取 得显著成果, 居民有更多的资金用于购买保 险, 除此之外, 保险品种的增多, 也对保险 资金的增加起到一定推动作用。

表 1 及图 2 反映了 2012-2016 年原保费 收入与赔付情况, 在保费收入增长的同时, 保险资金的赔付支出也相应增加, 二者增长 速度大致相同, 说明人们的利用保险降低风 险的意识越来越强。

表 1.2012-2016 年原保险资金收入与赔付情况 单位: 亿元

\begin{tabular}{|c|c|c|c|c|c|c|c|}
\hline \multirow{2}{*}{ 年份 } & \multicolumn{3}{|c|}{ 原保检保伟收入 } & \multicolumn{3}{|c|}{ 原保猃嘼付支出 } & \multirow{2}{*}{$\begin{array}{l}\text { 原保险保 } \\
\text { 带结余 }\end{array}$} \\
\hline & 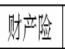 & 人身脸 & 㢵 & 财产险 & 人身险 & 合计 & \\
\hline 2012 & 5330.93 & 10157 & 15487.93 & 2816.33 & 1899.99 & 4716.32 & 10771.61 \\
\hline 2013 & 6212.26 & 11009.98 & 17222.24 & 3439.11 & 2773.77 & 6212.91 & 11009.33 \\
\hline 2014 & 7203.38 & 13031.43 & 20234.81 & 3788.21 & 3428 & 7216.21 & 13018.6 \\
\hline 2015 & 7994.97 & 16887.35 & 24882.52 & 4194.17 & 4479.97 & 8674.14 & 15608.38 \\
\hline 2016 & 8724,17 & 22179.99 & 30904,16 & 4729,48 & 5786.2 & 10515,68 & 20388.48 \\
\hline
\end{tabular}

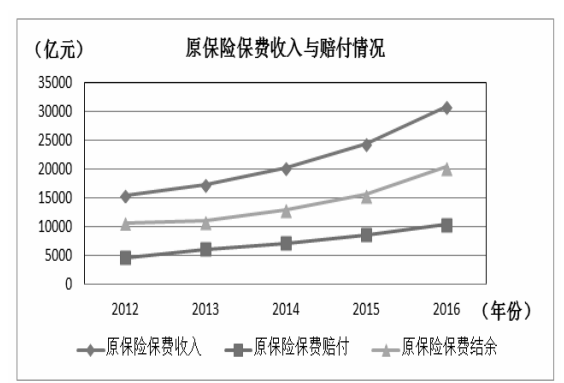

图 2. 2012-2016 年原保险资金收入与赔付 情况

尤其, 互联网时代支付结算的兴起与发 展, 人们更加注重自身财产安全性, 电子账 户保险几乎全民必备, 例如, 支付宝账户安 全险等。在财产险方面, 网络犯罪给人民的 财产造成巨大损失, 但是间接承担其损失的 却是保险公司, 更多时候保险公司还需要加 倍赔偿居民损失。

人身险方面, 医疗保险与意外险是两个 重要的险种, 也是赔付支出最多的险种。近 年来, 随着我国经济的发展, 也间接增加了 人们的生活成本, 人们面临巨大的生活压 
力, 越来越多的居民不得不过度消耗身体来 换取金钱，这也造成后期医疗支出的增加， 对于投保的人们来说, 其间接成本的承担者 依然是保险公司。意外险方面, 此处重点提 及交通事故, 近年来车辆数量的激增, 交通 事故频繁发生, 节假日更是交通事故多发 期, 车险及意外险等保险的投保者同样把成 本转嫁给了保险公司, 加大了保险公司的经 营成本。

表 2 及图 3 反映了 2012-2016 年, 我国 保险资金的具体运用情况。通过 5 年的数据, 我们可以发现, 企业债券的保险资金占有率 呈现逐年上升趋势，从 2012 年的 10899.98 亿元, 增加到 2016 年的 18627.99 亿元。企 业债券与银行债券和国债相比, 有更高的收 益, 但同时也面临更大的违约风险。企业债 券的持续增长, 一方面说明, 保险资金的利 用效率更高, 到期有更高的收益, 但是, 一 旦企业出现信任危机, 保险资金将会面临很 大损失。

表 2. 2012-2016 年保险资金运用情况 单位: 亿元

\begin{tabular}{|c|c|c|c|c|c|}
\hline 年代 & 银行存款 & 国债 & 金融渍券 & 企此债券 & 证券投资基金 \\
\hline 2012 & 23446 & 4795.02 & 14832.57 & 10899.98 & 3625.58 \\
\hline 2013 & 22640.98 & 4776.73 & 14811.84 & 13727.75 & 3575,52 \\
\hline 2014 & 25310.73 & 5009,88 & 15067.12 & 15460.13 & 4714.28 \\
\hline 2015 & 24349.67 & 5831.12 & 15215.31 & 17307.38 & 8856.5 \\
\hline 2016 & 24844.21 & 7796.24 & 16260.35 & 18627.99 & 8554,46 \\
\hline
\end{tabular}

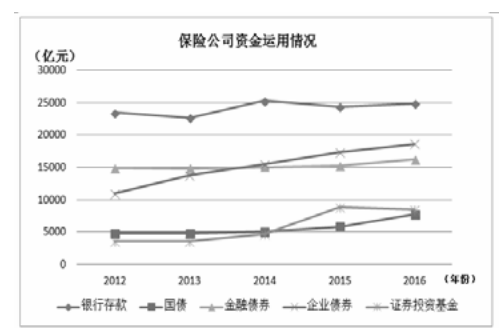

图 3. 2012-2016 年保险资金运用情况

2012-2016 年, 保险资金银行存款的金 额远高于其他项目, 且除 2013-2014 年, 银 行存款的数量增加较多外, 其余年份, 银行 存款的数量只出现小幅度增长。2012-2015 年，保险资金投资金融债券的金额基本保持 一致，2015-2016 年保险资金投资金融债券 的金额出现小幅上升。2012-2014 年, 保险
资金运用到证券投资基金的金额呈小幅上 升趋势, 2014-2015 年, 呈迅速上升趋势, 2015-2016 年基本保持不变。保险资金运用 渠道的变化, 同国家经济环境以及经济政策 息息相关。

\section{5. 国外保险资金的运用}

国外在保险资金运用方面主要有三种 模式。其一, 外部委托投资; 其二, 公司内 部设立投资部门; 其三, 设立专业化的保险 资产管理机构。

在美国, 保险公司资产总量一直具有向 上增长的趋势, 平均投资收益率保持在较高 的水平, 净投资收益率呈现递增的状态。美 国保险资金投资方式主要有四种, 它们分别 是债券、股票、抵押贷款和不动产投资。在 美国保险公司的资金运用中, 贷款的比例呈 现下降的特点和股票的投资比例呈现上升 的特点, 并且债券的投资比重最大。其中公 司债券和政府债券占了巨大比重并且债券 的质量高。

英国作为保险业的发源地, 是保险资金 运用最为自由、宽松的国家。在英国, 保险 公司的投资也是较为宽泛的。因此, 目前英 国保险公司的资金运用涉及方面广泛: 金融 资产、实物资产、资本市场工具、货币市场 工具、证券类资产、非证券类资产等等。

在英国当局统计的数据中将英国保险 公司分为长期保险公司和一般保险公司。长 期保险公司的资金运用主要是以普通股为 主。英国保险公司的资金运用是一种多元化 的投资, 既在给保险公司资金运用分散风险 基础上带来稳定可观的收益, 又能确保实现 保险公司的偿还能力。

德国是以间接金融为主, 德国拥有强大 的银行体系, 因此商业银行在信贷市场和资 本市场处于主导地位。德国金融体系整体特 征表现为平和稳健。平稳的金融环境为德国 保险公司提供了稳定的投资环境, 但投资整 体的市场回报率较低。由于德国监管部门对 其采取了严格的事前监管模式, 为保险公司 规定了十分具体准确的资金运用的许可范 围、可选择币种等, 并对投资于证券资产及 特别资产，外国公司股票及债券等金融资 产, 以及实物资产规定了准确的投资比例。 
相应的，德国的保险投资收益也十分稳定， 其市场收益的变动幅度在保险市场的发达 国家相对较低, 但是随着德国金融体系结构 的变化, 为了提高自身竞争力, 为了适应当 下论诱多变的全球金融环境, 为了满足欧盟 共同市场的内在需求, 德国保险公司也在增 加对股票等高收益率的金融工具的投资。

日本具有较成熟的保险市场, 利用率较 高, 没有多余闲置的资金是日本保险资金运 用鲜明的特征。在日本保险公司资金运用 中，对于有价证券的资金运用的所占比例最 大, 且具有增长的趋势。在过去的日本, 最 受欢迎的资金运用方式是贷款。然而在经历 “泡沫经济时代” 日本民众无力偿还拖欠之 后, 日本保险公司逐渐减少贷款业务。同时 加大了对海外债券、基金、证券等方面的投 资, 但是随着日本货币的升值, 日本保险公 司面临着新的汇率风险, 遭受了巨大的投资 损失。然而由于日本的国内利率非常低且国 内证券市场的萎靡, 保险公司也面临着巨大 的投资压力, 于是近些年日本保险公司逐步 关注海外投资。日本保险资金运用针对于保 险贷款的投资比重逐渐减少, 取而代之的是 针对于证券投资的比重逐渐上升, 特别是对 那些收益比较好, 得到广泛关注和认可的投 资方式更加关注。当前, 日本保险业主要投 资方式是针对贷款、房地产及有价证券, 而 房地产投资比例呈现下降的趋势。

\section{6. 我国保险资金运用中存在的问题}

\section{1 保险资金运用的监管体系不完善}

保险资金的监管最重要的是保证保险 资金的安全性，保险资金的用途合理合法， 且可以通过保险资金的投资达到增加保险 业利润的目的。但目前, 我国保险资金的监 管存在很大问题, 例如, “宝万之争” 造成 保险资金过度浪费，导致保险资金成为个人 谋取私欲的工具。一方面由于我国保险立法 相对滞后, 相关部门在事故发生后才发现其 中的问题, 造成许多人游走在法律的边缘地 带, 给国家财产造成极大损失。

\section{2 保险公司内部治理结构存在问题}

与发达国家相比, 我国保险市场的发展
还不成熟, 部分保险公司缺乏有效的治理结 构, 采取激进经营、激进投资的策略, 导致 业务快进快出、风险敞口过大以及流动性的 问题。上文图 3 显示, 从 2012-2016 年, 我 国保险业用于购买企业债券的资金呈现大 幅上升趋势, 5 年间上升了 7728 亿元, 其中 一个原因就是公司管理层激进投资的策略。 与金融债券和国债相比，虽然企业债券到期 有更高的收益, 但存在更高的违约风险, 一 旦发生违约事件，保险资金将面临巨大损 失。

\section{3 信用风险日益凸显}

债券市场违约频发, 保险资金投资组合 风险敞口加大。我国保险资金约 80\%购买配 置于信用资产, 在我国债券违约进入多发 期, 保险公司投资基础设施债券、不动产投 资计划和信托产品的信用风险 ${ }^{[9]}$ 敞口提升。 2014 年以前信用债务长期处于 “刚性兄付” 状态, 没有违约事件。受经济周期影响, 2015 年发生 22 起实质性违约事件, 涉及金额 120 亿元。2016 年违约开始加快, 仅前 5 个月共 有 30 只债券违约, 涉及本金超过 200 亿元。

我国保险资金运用中存在的问题, 严重 阻碍了保险市场健康有序发展, 侵害了投保 人的利益。因此, 针对保险业存在的问题, 提出相应解决措施尤为重要。

\section{7. 对策建议}

\section{1 加强保险市场的监管}

十九大以来, 国家出台了各项规定, 规 范保险业的健康运行, 但是, 我国保险资金 在运用的监管体系仍不完善, 特别是缺乏有 效的资产负债匹配风险相关监管法律法规。 随着互联网的兴起, 加强对金融业的监管尤 为重要, 保险业是我国金融体系的重要构成 部分, 需要国家强有力的措施实现保险业的 长远发展。所以, 首先应该健全保险业相关 法律制度建设, 给保险业提供相对理想的法 律环境。其次, 应该大力实施金融创新, 为 保险业的发展提供相对稳定的金融环境。

\section{2 优化保险资金投资结构}

我国保险资金投入银行存款和债券的 
比率很高, 2017 年银行存款和债券的资金占 用比达到 $47.51 \%$ 。其中, 银行存款的占有重 要比率, 证券投资比例相对较小。由于银行 存款利息率远不如投资证券的利润高, 因 此, 我国保险业资金运用效率较差 ${ }^{[10]}$, 容易 造成资源浪费。在保险业在发展过程中, 我 们可以借鉴美国经验，优化投资结构，加大 股票投资在总投资中的比重，增加保险资金 的盈利能力。其次吸收美国 “次贷危机” 的 教训, 降低贷款资金总额, 保险公司在发放 贷款前, 要充分调查借款公司的偿债能力以 及信用状况, 对信用等级低的公司拒绝发放 贷款, 保证资金的安全性。

\section{3 拓宽保险资金的运用渠道}

目前, 我国保险资金的运用渠道相对较 窄, 主要运用渠道包括: 银行存款、债券 (包 括国债、金融债、企业债等)、证券投资基 金、股票、基础设施投资计划、集合资金信 托计划、商业银行理财产品等另类投资、境 外投资等。与英国相比, 我国保险业在很多 业务仍存在空白。所以, 在保险资金投资过 程中, 应实施多元化的投资战略, 分散投资 风险。

\section{4 加强保险风险管理能力}

保险资产管理机构要把风险管理摆在 首位, 完善风险管理制度建设 ${ }^{[11]}$, 加强执行 力监督, 提高风险管理能力。首先, 要完善 资金运用系统，将监管要素指标固化于资金 运用系统, 尽可能将操作风险降到最低, 同 时提高投资交易的效率。其次, 要加强资产 负债协调管理，使前端资产投资运作与后端 负债开发产品协调一致, 做好产品定价风险 与利差损风险的防范。

基金资助: 本文获得云南省科技计划面 上项目 (2017FB103), 云南省哲学社会科学 规划项目 (YB2016016), 云南师范大学 “登 峰扎根” 优秀科研创新团队建设项目, 中国 博士后科学基金资助项目（2017M623079）, 云南师范大学博士科研启动项目的资助。

\section{参考文献}

[1] 胡宏兵,郭金龙. 我国保险资金运用问题 研究- - 基于资产负债匹配管理的视角. 宏观经济研究,2009,(11):51-58.

[2]王姝.我国保险资金运用及监管分析 - - 基于国际经验的借鉴. 经济体制改 革,2013,(3):164-168.

[3] 黄英君.我国保险资金运用的风险理论 研究-一基于 VaR 模型的实证分析.云 南财经大学学报,2010,26(3):94-102.

[4] 靳珂.我国保险投资组合风险管理:基于 VaR 的研究. 河南社会科学, 2016, 24(2):95-102.

[5] 张健.保险资金运用全面风险管理- 基于机制建设的角度.保险研究 2009, (3):71-76.

[6] 杨明生.对保险资金运用与监管的思考. 保险研究,2008,(8):74-77.

[7] 曲扬.保险资金运用的国际比较与启示. 保险研究,2008,(6):83-85.

[8] 张立勇.发达国家保险资金运用主要做 法中国化的思考. 保险研究，2012， (8):89-94.

[9] Huang C F. Types of credit risks and strategies to improve risk identification by internet of intelligences. Journal of Risk Analysis and Crisis Response, 2013, 3(5):41-51.

[10] Huy D T N. The volatility of market risk in viet nam listed banking, insurance and financial services company groups after the financial crisis 2009-2011. Journal of Risk Analysis and Crisis Response, 2013, 3(3): 127-134.

[11] Takeshita J I, Mohri H, A Cooperative Game Theoretical Approach to Risk Analysis, Using Network Structure. Journal of Risk Analysis and Crisis Response, 2014, 4(1):43-48. 